\title{
Prevalence of obesity and need for screening using tools like Indian Diabetes Risk Scale in Diabetes prevention among medical students
} Vikrant Prabhakar ${ }^{1}$, Amrit Virk ${ }^{2}$, Parmal Saini ${ }^{3}$

${ }^{1}$ Associate Professor, Department of Community Medicine, Adesh Medical College, Kurukshetra, Haryana; ${ }^{2}$ Professor, Department of Community Medicine, Adesh Medical College, Haryana Kurukshetra; ${ }^{3}$ Assistant Professor, Department of Community Medicine, Adesh Medical College, Kurukshetra, Haryana

\begin{tabular}{|c|c|c|c|c|c|c|c|}
\hline Abstract & Introduction & Methodology & Results & Conclusion & $\underline{\text { References }}$ & Citation & Tables / Figures \\
\hline \multicolumn{8}{|c|}{ ng Author } \\
\hline \multicolumn{7}{|c|}{$\begin{array}{l}\text { Dr. Parmal Saini, Ph.D, Assistant Professor, Department of Community Medicine, Adesh Medical College, } \\
\text { Kurukshetra, Haryana - } 136135 \\
\text { E Mail ID: sainiparmal@gmail.com }\end{array}$} & 回语回 \\
\hline
\end{tabular}

\section{Citation}

Prabhakar V, Virk A, Saini P. Prevalence of obesity and need for screening using tools like Indian Diabetes Risk Scale in Diabetes prevention among medical students Indian J Comm Health. 2020;32(2):348-353.

Source of Funding: Nil Conflict of Interest: None declared

\section{Article Cycle}

Received: 19/12/2019; Revision: 07/04/2020; Accepted: 20/05/2020; Published: 30/06/2020

This work is licensed under a Creative Commons Attribution 4.0 International License.

\section{Abstract}

Introduction: The prevalence of lifestyle diseases in increasing throughout the world. They are increasingly taking over communicable diseases as the major cause of morbidity and mortality. Medical students usually have sedentary lifestyle coupled with high level of stress, owing to academic requirements. Hence, they are at a much higher risk of developing lifestyle diseases. Materials and Methods: Study subjects were administered a validated questionnaire to collect information related with the components of IDRS. Based on the score, they were divided into high risk, moderate risk and low risk. Data was analysed using the SPSS version 21. Result: Half of all the students were in the moderate risk group. The rest was distributed among low risk (17.33\%) and high risk (27.33\%). Among those with low risk of developing T2DM, 73\% were males, whereas females constituted $70.7 \%$ of those with high risk of developing T2DM. The association of developing T2DM was also highly significant with obesity. Statistically significant association of high T2DM risk were found with gender being female, family history of T2DM and BMI $\geq 23 \mathrm{Kg} / \mathrm{m} 2$ Conclusion: IDRS has been shown to be an effective tool for screening populations. Hence, regular programs with IDRS along with blood sugar and lipid profile of moderate and high risk group along with stress management can be effective in supporting medical students to cope with demanding study and work conditions among medical students and doctors.

\section{Keywords}

Diabetes Mellitus Type II; Risk Factors; Medical Students; IDRS

\section{Introduction}

The prevalence of lifestyle diseases in increasing throughout the world. They are increasingly taking over communicable diseases as the major cause of morbidity and mortality. These diseases have multifactorial aetiology. Obesity, stress, sedentary life style, eating habits and family history are considered to be an important risk factor in the development of lifestyle diseases.

Diabetes Mellitus Type 2 (T2DM) is one of the major lifestyle diseases and a major cause of fatal and non-fatal complications. As per the latest reports, over $19 \%$ of the world's diabetic population lives in India, which translates to over 35 million diabetic patients, and is projected to increase to 80 million by the year 2030 (1).

Medical students usually have sedentary lifestyle coupled with high level of stress, owing to academic requirements. Medical Colleges are known to be stressful environment for students (2), because of long working hours, lack of sleep, fear of failure, lack of peer support and exposure to practical education sessions very different from those experienced in the school classrooms. Hence, they are at a much higher risk of developing lifestyle diseases.

Obesity has been consistently associated with high prevalence and incidence of lifestyle diseases (3). Measuring a person's waist circumference (WC) is the simplest way to assess central obesity. WC has been shown to be one of the most accurate anthropometrical 
indicators of abdominal fat and predictor of risk of developing T2DM (4), better than BMI (5). It is closely correlated to the waist to hip ratio (WHR), but is thought to be a more reliable measure of abdominal fat; the WHR can mask the status of abdominal obesity with a disproportionately large hip circumference (6). People with higher BMI tend to develop T2DM at a younger age (7).

Numerous studies have shown that lifestyle interventions has impact on preventing and modifying the course of the disease. In a multicentre clinical research study, The Diabetes Prevention Program, Lifestyle interventions showed a reduction of $58 \%$ in the risk of diabetes as compared to a $31 \%$ reduction in the group administered Metformin (8). A recent multicentre randomized control trial found that intensive lifestyle interventions (ILI) led to significant weight loss and improvement in fitness in individuals with T2DM as compared to the control group with diabetes support and education (DSE). Over the four years of study, ILI subjects had better level of glycaemic control, blood pressure, HDL-C and triglycerides (9). The Indian Diabetes Prevention Program has also shown similar results (10). Yu et al found that the total healthcare cost declined by $\$ 213$ per person per year for a weight loss of $1 \%$ in T2DM (11).

Indian Diabetes Risk Score (IDRS), devised and developed by Mohan et al. at the Madras Diabetes Research Foundation (MDRF), is a validated tool to identify individuals with high risk of developing T2DM in future. It takes into consideration family history, waist circumference, age and physical activity to identify individuals at high risk of developing diabetes (12) and can be an efficient tool to reduce the risk of diabetes (13). High risk individuals identified using IDRS can be counselled to reduce the risk of diabetes. (Table 1 )

Using IDRS as screening tool among medical students has shown reduction in mean abdominal circumference by $1.47 \pm 1.14 \mathrm{~cm}$ and decrease in mean calorie consumption $176 \pm 87 \mathrm{kcal}$ along with increase in physical activities. All these contributing to reduction of mean risk score from 36 to 31 (14).

\section{Aims \& Objectives}

1. To assess risk of type 2 diabetes mellitus (T2DM) using the IDRS among Medical Students

2. To study association of other risk factors based on IDRS results.

\section{Material \& Methods}

The current study was done in a medical college in north India. Convenient sampling method was used to identify the study population. All the students coming to the department of Community Medicine in their clinical postings and gave informed consent were included and administered a validated questionnaire to collect information related with the components of IDRS. Their waist circumference was measured and IDRS calculated.
Grades of BMI (modified for Asians) were used (15). Based on the score, they were divided into high risk (score $>60$ ), moderate risk (score between 30-50) and low risk (score $<30$ ). Anthropometric measurements (height, weight, waist circumference, hip circumference and blood pressure) were measured using standard methods and noted. Data were entered and analysed using the SPSS version 21. Quantitative data were expressed as mean and standard deviation and $95 \%$ confidence interval $(\mathrm{Cl})$ was calculated. Qualitative data were expressed as percentage/proportion and the Chi-square test $(\chi 2)$ was used to assess statistical significance of results. ' $P$ ' $<0.05$ (0.01) was considered statistically significant (highly significant).

\section{Results}

150 medical students (68 male (45.3\%) and 82 females $(54.7 \%))$ gave informed consent and were included. The results have been tabulated below

(Table 2) shows that of all the male study subjects, $73.5 \%$ had waist line less than $90 \mathrm{~cm}$ and $14.7 \%$ had it above 100 cms. Of the females, $23.2 \%$ had it less than $80 \mathrm{cms}$ whereas $37.8 \%$ measured above $90 \mathrm{cms}$.

(Table 3 ) shows the distribution of risk of T2DM among study subjects. Half of all the students were in the moderate risk group. The rest was distributed among low risk (17.33\%) and high risk (27.33\%).

(Table 4) shows the distribution of characteristics among study subjects. Among those with low risk of developing T2DM, 73\% were males, whereas females constituted $70.7 \%$ of those with high risk of developing T2DM. The association of developing T2DM was also highly significant with obesity, with more than half of obese students had high risk of developing T2DM.

(Table 5) shows statistically significant association of high T2DM risk with the gender being female $(P=0.015)$, family history of T2DM $(P \leq 0.001)$ and $B M I \geq 23 \mathrm{Kg} / \mathrm{m} 2(P \leq 0.001)$

\section{Discussion}

Present study shows that 26 (17.33\%), 83 (55.33\%) and 41 $(27.33 \%)$ subjects were in low, moderate and high-risk category to develop T2DM as per the IDRS. Findings for high-risk category in our study were much higher than from the study conducted by Singh et al. (1\%) (16), Gopalakrishnan et al. (1.9\%) (17) and Bhatia et al. (1\%) (18).Studies by Subramani et al., Kumar et al., Mohan et al. and Chowdhury et al., showed $12.1 \%$ (19), 18.6\% (20), $31.2 \%$ (21) and $31.5 \%$ (22) in high-risk category, respectively. Dissimilar observation for moderate-risk category were found in the study conducted by Vardhan et al. at (28\%) (14). However, similar figures for moderaterisk category were found in studies conducted by Chowdhury et al. (46\%), Mohan et al. (50.3\%) (21), Bhatia et al. (68\%) (18) and Subramani et al. (74.7\%) (19) (22). There is a statistically significant association of moderate to high risk of developing T2DM with being female ( $P=$ $0.011)$ and with higher $\mathrm{BMI}(P=0.009)$. This is very 
different from other studies. Singh et al found statistically significant association of moderate-high diabetes risk with male gender and with higher BMI (16). Similar statistically significant association between male gender and higher BMI with increased diabetes risk was present in a study conducted by Gopalakrishnan et al. (17) and Chowdhury et al(22). This dissimilar finding in the present study may be due to the fact that almost three-fourth of the female subjects had waist measurement above $80 \mathrm{cms}$.

The risk of developing T2DM with positive family history of diabetes in our study was found to be highly significant (20/33 (60.6\%), P<0.001). Studies have also shown family history as an independent risk factor for T2DM (23), which is being corroborated in our study also. Though other studies conducted by Subramani et al. (16.6\%) (19), Bhatia et al. (32\%) (18), Gopalakrishnan et al. (46.6\%) (17)\& Singh et al (41.5\%) (16) have found positive family history of diabetes in subjects with high risk of developing T2DM, the proportion was much higher in our study and is similar to study by Adhikari et al. which showed that $45-80 \%$ children who develop T2DM had a parent with the disease (24).

In our study, vigorous, moderate, mild and no physical activity was carried out by 4 (2.67\%), 53 (35.33\%), 66 (44\%) and 27 (18\%) subjects, respectively. Association between no/mild physical activity and moderate-high diabetes risk was statistically significant $(P<0.0001)$. Our study corroborates with the findings from several studies which have shown that physical activity less than the recommended values for moderate exercise $(<150 \mathrm{~min}$ per week) does increase the risk of T2DM. Findings for moderate physical activity are similar to results of study conducted by Singh et al (31\%) (16) and Bhatia et al. (49\%) (18).Higher figure for moderate physical activity was seen in a study conducted by Gopalakrishnan et al. (76.5\%) (17) and Subramani et al. (74.7\%) (19).

\section{Conclusion}

IDRS has been shown to be an effective tool for screening populations. Hence, regular programs with IDRS along with blood sugar and lipid profile of moderate and high risk group along with stress management can be effective in supporting medical students to cope with demanding study and work conditions among medical students and doctors. In recent years, Medical Council of India $(\mathrm{MCl})$ has shown greater concerns for well-being of medical students. Various programs have been introduced in medical colleges to support students. Supplementing them with such lifestyle intervention programs will further augment $\mathrm{MCl}^{\prime}$ s effort in ensuring students well-being.

\section{Recommendation}

There has been increasing awareness about lifestyle diseases. Early adoption of healthy lifestyle, especially among those who are at a higher risk of developing such diseases has been found to be preventive. Not only does it delays the onset of disease, but also decelerates the progress and long term consequences. Conducting such assessments in medical students can go a long way in increasing awareness among students and motivating them in adopting preventive measures. It can also help in early identification and treatment of disease.

\section{Limitation of the study}

The study was conducted among medical students who have good knowledge about diseases and its prevention and are likely to understand and adopt lifestyle interventions. Such targeted group interventions will be cost effective and have significant impact. However, it will not be easy to convince general population without putting efforts. Cost of lifestyle interventions, as calculated by Wolf et al, was $\$ 328$ per person per year (25). Though this cost will be negated by lower healthcare use and lesser hospital admissions, it needs to be seen how an efficient and effective behaviour change program can be designed to induce healthy lifestyle practices. Cross-sectional analysis does not permit observation of trend of diabetes risk among the subjects over time. Also, as the study was conducted in the younger age group, so the effect of age on diabetes risk could not be considered.

\section{Relevance of the study}

With evolution of better living conditions and availability of health care services, lifestyle diseases are increasingly becoming more important public health concern, as compared to infectious diseases. Tools like IDRS have the potential to identify the risk of developing T2DM and other lifestyle diseases, so that steps can be taken to promote primordial preventative measures and prevent or delay the onset of disease and its consequences. The current study is an attempt to find the strength of association of known risk factors of T2DM with IDRS in a select group. This, and other such studies will help in identifying wider applicability of IDRS and its use for preventing T2DM and its long term health effects.

\section{Authors Contribution}

All the authors have contributed significantly for the designing the study, implementing it, collecting data and analyzing data as well as repairing the final document.

\section{References}

1. Wild S, Roglic G, Green A, Sicree R, King H. Global prevalence of diabetes: estimates for the year 2000 and projections for 2030 . Diabetes Care. 2004 May;27(5):1047-53. doi: 10.2337/diacare.27.5.1047. PubMed PMID: 15111519.[PubMed]

2. Sayeedunnisa Sarah, Sultan Rizwan Ahmad, A. Chandrasekhar. Prevalence of Anxiety and Depression Among Medical Students Of Deccan Medical College, Hyderabad. Nat J Res Community Med 2018;7(3):229-232.

3. Vazquez G, Duval S, Jacobs DR Jr, Silventoinen K. Comparison of body mass index, waist circumference, and waist/hip ratio in predicting incident diabetes: a meta-analysis. Epidemiol Rev. 2007;29:115-28. doi: 10.1093/epirev/mxm008. Epub 2007 May 10. Review. PubMed PMID: 17494056.[PubMed].

4. Mamtani MR, Kulkarni HR. Predictive performance of anthropometric indexes of central obesity for the risk of type 2 diabetes. Arch Med Res. 2005;36:581-9. 
5. Geneva: World Health Organization; 2008. World Health Organization (WHO). Waist Circumference and Waist-Hip Ratio. Report of WHO Expert Consultation.

6. Kurpad SS, Tandon H, Srinivasan K. Waist circumference correlates better with body mass index than waist-to-hip ratio in Asian Indians. Natl Med J India. 2003 Jul-Aug;16(4):189-92. PubMed PMID: 14606765.[PubMed].

7. Rhee EJ. Diabetes in Asians. Endocrinol Metab (Seoul). 2015 Sep;30(3):263-9. doi: 10.3803/EnM.2015.30.3.263. Review. PubMed PMID: 26435131; PubMed Central PMCID: PMC4595349.[PubMed].

8. The Diabetes Prevention Program. Design and methods for a clinical trial in the prevention of type 2 diabetes. Diabetes Care. 1999 Apr;22(4):623-34. doi: 10.2337/diacare.22.4.623. PubMed PMID: 10189543; PubMed Central PMCID: PMC1351026.[PubMed]

9. Wing RR. Long-term effects of a lifestyle intervention on weight and cardiovascular risk factors in individuals with type 2 diabetes mellitus: four-year results of the Look AHEAD trial. Arch Intern Med. $\quad 2010 \quad$ Sep 27;170(17):1566-75. doi 10.1001/archinternmed.2010.334. PubMed PMID: 20876408; PubMed Central PMCID: PMC3084497.[PubMed].

10. Ramachandran A, Snehalatha C, Mary S, Mukesh B, Bhaskar AD, Vijay V. The Indian Diabetes Prevention Programme shows that lifestyle modification and metformin prevent type 2 diabetes in Asian Indian subjects with impaired glucose tolerance (IDPP-1). Diabetologia. 2006 Feb;49(2):289-97. doi: 10.1007/s00125-0050097-z. Epub 2006 Jan 4. PubMed PMID: 16391903.[PubMed].

11. Yu AP, Wu EQ, Birnbaum HG, Emani $S$, Fay M, Pohl G, Wintle $M$, Yang E, Oglesby A. Short-term economic impact of body weight change among patients with type 2 diabetes treated with antidiabetic agents: analysis using claims, laboratory, and medical record data. Curr Med Res Opin. 2007 Sep;23(9):2157-69. doi: 10.1185/0300799007X219544. Review. PubMed PMID: 17669232. [PubMed]

12. Mohan V, Deepa R, Deepa M, Somannavar S, Datta M. A simplified Indian Diabetes Risk Score for screening for undiagnosed diabetic subjects. J Assoc Physicians India. 2005 Sep;53:759-63. PubMed PMID: 16334618.[PubMed]

13. Dhiren V. Amin, M.P. Singh DNPMCSGNA. A study on validity of Indian Diabetes Risk Score (MDRF) for screening of Diabetes Mellitus among the high risk group (policemen) of Diabetes Mellitus of Bhavnagar city. Innovative Journal of Medical and Health Sciences. 2013;2(5): 109-111.

14. Vardhan A, Prabha M R A, Shashidhar M K, Shankar N, Gupta S, Tripathy A. Value of Indian Diabetes Risk Score among Medical Students and Its Correlation with Fasting Plasma Glucose, Blood Pressure and Lipid Profile. J Clin Diagn Res. 2012 Nov;6(9):1528-30. doi: 10.7860/JCDR/2012/4264.2550. PubMed PMID: 23285447; PubMed Central PMCID: PMC3527787.[PubMed].

15. Geissler C, Powers HJ, editors. Human Nutrition: Obesity. 13th ed. Vol. 20. United Kingdom: Oxford University Press; 2017. 406-23
16

$$
\text { Singh MM, Mangla V, Pangtey R, Garg S. Risk Assessment of }
$$
Diabetes Using the Indian Diabetes Risk Score: A Study on Young Medical Students from Northern India. Indian J Endocrinol Metab. 2019 Jan-Feb;23(1):86-90. doi: 10.4103/ijem.IJEM_623_18. PubMed PMID: 31016160; PubMed Central PMCID: PMC6446666.[PubMed].

17. Gopalakrishnan S, Rama R, Muthulakshmi M. Assessing the risk of developing type 2 diabetes mellitus among medical students in Chennai using Indian diabetes risk score. Int J Community Med Public Health. 2017;4:2366-72.

18. Bhatia T, Maitreyi O, Vimisha D, Sonalika B, Gerhard F, Vaidehi L, et al. Type 2 diabetes mellitus: Risk evaluation and advice in undergraduate students in Mumbai. Int J Pharm Sci Invent. 2014:3:37-40.

19. Subramani R, Devi U, Shankar U, Stephen T, Karthik RC, Seshadhri $\mathrm{S}$, et al. Assessment of risk of type 2 diabetes mellitus among rural population in Tamil Nadu by using Indian Diabetic Risk Score. Middle-East J Sci Res. 2014;21:223-5.

20. Gupta SK, Singh Z, Purty AJ, Vishwanathan M. Diabetes prevalence and its risk factors in urban Pondicherry. Int J Diabetes Dev Ctries. 2009 Oct;29(4):166-9. doi: 10.4103/0973-3930.57348. PubMed PMID: 20336199; PubMed Central PMCID: PMC2839131. [PubMed].

21. Mohan V, Sandeep S, Deepa R, Shah B, Varghese C. Epidemiology of type 2 diabetes: Indian scenario. Indian J Med Res. 2007 Mar;125(3):217-30. PubMed PMID: 17496352.[PubMed]

22. Chowdhury R, Mukherjee A, Lahiri SK. A study on distribution and determinants of Indian Diabetic Risk Score (IDRS) among rural population of West Bengal. National J Med Res. 2012;2:282-6.

23. Scott RA, Langenberg C, Sharp SJ, Franks PW, Rolandsson O, Drogan D, van der Schouw YT, Ekelund U, Kerrison ND, Ardanaz E, Arriola L, Balkau B, Barricarte A, Barroso I, Bendinelli B, Beulens JW, Boeing $H$, de Lauzon-Guillain B, Deloukas P, Fagherazzi G, Gonzalez C, Griffin SJ, Groop LC, Halkjaer J, Huerta JM, Kaaks R, Khaw KT, Krogh V, Nilsson PM, Norat T, Overvad K, Panico S, Rodriguez-Suarez L, Romaguera D, Romieu I, Sacerdote C, Sánchez MJ, Spijkerman AM, Teucher B, Tjonneland A, Tumino R, van der A DL, Wark PA, McCarthy MI, Riboli E, Wareham NJ. The link between family history and risk of type 2 diabetes is not explained by anthropometric, lifestyle or genetic risk factors: the EPIC-InterAct study. Diabetologia. 2013 Jan;56(1):60-9. doi: 10.1007/s00125012-2715-x. Epub 2012 Sep 28. PubMed PMID: 23052052; PubMed Central PMCID: PMC4038917.[PubMed].

24. Adhikari P, Pathak R, Kotian S. Validation of the MDRF-Indian Diabetes Risk Score (IDRS) in another south Indian population through the Boloor Diabetes Study (BDS). J Assoc Physicians India. 2010 Jul;58:434-6. PubMed PMID: 21121209.[PubMed]

25. Wolf AM, Siadaty M, Yaeger B, Conaway MR, Crowther JQ, Nadler $\mathrm{JL}$, Bovbjerg VE. Effects of lifestyle intervention on health care costs: Improving Control with Activity and Nutrition (ICAN). J Am Diet Assoc. 2007 Aug;107(8):1365-73. doi: 10.1016/j.jada.2007.05.015. PubMed PMID: 17659904.[PubMed].

\section{Tables}

\section{TABLE 1 MDRF-IDRS (12)}

\begin{tabular}{|c|c|}
\hline Particulars & Score \\
\hline \multicolumn{2}{|l|}{ Age } \\
\hline$<35$ & 0 \\
\hline $35-49$ & 20 \\
\hline$>=50$ & 30 \\
\hline \multicolumn{2}{|l|}{ Abdominal Obesity } \\
\hline Waist <80 cm (females), $<90 \mathrm{~cm}$ (males) & 0 \\
\hline Waist $>80-89 \mathrm{~cm}$ (females), >90-99 cm (males) & 20 \\
\hline Waist $>=90 \mathrm{~cm}$ (females), >=100 cm (males) & 30 \\
\hline \multicolumn{2}{|l|}{ Physical Activity } \\
\hline Exercise + Strenuous work & 0 \\
\hline Exercise or Strenuous work & 20 \\
\hline
\end{tabular}




\section{TABLE 2 RISK SCORE COMPONENT OF STUDY SUBJECTS ( $\mathrm{N}=150)$}

\begin{tabular}{|l|l|l|}
\hline WDRS component & No of Students $(\mathbf{n})$ & \\
\hline$\leq 90$ & 50 & 73.5 \\
\hline $91-99$ & 8 & 11.8 \\
\hline$\geq 100$ & 10 & 14.7 \\
\hline Total & 68 & 100 \\
\hline Waist Circumference (cm) of Females & & \\
\hline$\leq 80$ & 19 & 23.2 \\
\hline $81-89$ & 32 & 39 \\
\hline$\geq 90$ & 31 & 37.8 \\
\hline Total & 82 & 100 \\
\hline Physical Activities of the Study Participants & & \\
\hline Vigorous & 4 & 2.67 \\
\hline Moderate & 53 & 35.33 \\
\hline Mild & 66 & 44 \\
\hline No & 27 & 18 \\
\hline Total & 150 & 100 \\
\hline Family History of Diabetes Mellitus & & \\
\hline No Family History & 117 & 78 \\
\hline Either parents & 31 & 20.67 \\
\hline Both Parents & 2 & 1.33 \\
\hline Total & 150 & 100 \\
\hline
\end{tabular}

TABLE 3 DISTRIBUTION OF STUDY SUBJECTS ACCORDING TO RISK GROUPS ( $N=150$ )

\begin{tabular}{|l|l|l|l|}
\hline Group (Risk Score) & No of Students (n) & Percentage (\%) & Mean Risk Score \\
\hline Group-I (<30, Low Risk) & 26 & 17.33 & 18.46 \\
\hline Group-II (30-50, Moderate Risk) & 83 & 55.33 & 37.71 \\
\hline Group-III ( $\geq 60$, High Risk) & 41 & 27.33 & 64.39 \\
\hline
\end{tabular}

TABLE 4 DISTRIBUTION OF CHARACTERISTICS AMONG STUDY SUBJECTS WITH IDRS ( $\mathrm{N}=150)$

\begin{tabular}{|c|c|c|c|c|c|c|c|c|c|}
\hline \multirow[t]{2}{*}{ Parameters } & \multicolumn{2}{|l|}{ Low Risk } & \multicolumn{2}{|c|}{ Moderate Risk } & \multicolumn{2}{|l|}{ High Risk } & \multicolumn{2}{|l|}{ Total } & \multirow{2}{*}{$\begin{array}{l}P \\
\text { Value }\end{array}$} \\
\hline & Number & $\%$ & Number & $\%$ & Number & $\%$ & Number & $\%$ & \\
\hline \multicolumn{10}{|l|}{ Gender } \\
\hline Females & 7 & $26.90 \%$ & 46 & $55.40 \%$ & 29 & $70.70 \%$ & 82 & $54.70 \%$ & \multirow{3}{*}{$\begin{array}{l}0.002 \\
*\end{array}$} \\
\hline Males & 19 & $73.10 \%$ & 37 & $44.60 \%$ & 12 & $29.30 \%$ & 68 & $45.30 \%$ & \\
\hline Total & 26 & $100.00 \%$ & 83 & $100.00 \%$ & 41 & $100.00 \%$ & 150 & $100.00 \%$ & \\
\hline \multicolumn{10}{|c|}{ Body Mass Index (BMI) as per modified Asian criteria } \\
\hline $\begin{array}{l}\text { Underweight } \\
(<18.5)\end{array}$ & 2 & $7.70 \%$ & 1 & $1.20 \%$ & 0 & $0.00 \%$ & 3 & $2.00 \%$ & \multirow[t]{4}{*}{$\begin{array}{l}<0.00 \\
1^{*}\end{array}$} \\
\hline $\begin{array}{l}\text { Normal } \\
\text { Weight (18.5- } \\
\text { 22.9) }\end{array}$ & 11 & $42.30 \%$ & 25 & $30.10 \%$ & 4 & $9.80 \%$ & 40 & $26.70 \%$ & \\
\hline $\begin{array}{l}\text { Over Weight } \\
(22.9-27.5)\end{array}$ & 8 & $30.80 \%$ & 42 & $50.60 \%$ & 15 & $36.60 \%$ & 65 & $43.30 \%$ & \\
\hline Obese (>27.5) & 5 & $19.20 \%$ & 15 & $18.10 \%$ & 22 & $53.70 \%$ & 42 & $28.00 \%$ & \\
\hline Total & 26 & $100.00 \%$ & 83 & $100.00 \%$ & 41 & $100.00 \%$ & 150 & $100.00 \%$ & \\
\hline
\end{tabular}


TABLE 5 ASSOCIATION OF CHARACTERISTICS AMONG STUDY SUBJECTS WITH IDRS ( $N=150)$

\begin{tabular}{|c|c|c|c|c|c|c|c|c|}
\hline Characteristic & $\begin{array}{l}\text { High Risk } \\
\text { (\%) }\end{array}$ & $\begin{array}{l}\text { Moderate } \\
\text { to Low } \\
\text { Risk (\%) }\end{array}$ & Total (\%) & $\begin{array}{l}\text { Odds Ratio } \\
\text { (Unadjusted) }\end{array}$ & $95 \% \mathrm{Cl}$ & Chi Square & $\begin{array}{l}\text { d } \\
\text { f. }\end{array}$ & P Value \\
\hline \multicolumn{9}{|l|}{ Gender } \\
\hline Males & $12(17.6)$ & $56(82.35)$ & $68(100)$ & \multirow{2}{*}{0.392} & \multirow{2}{*}{$0.181-0.846$} & \multirow{2}{*}{5.876} & \multirow{2}{*}{1} & \multirow{2}{*}{$0.015^{*}$} \\
\hline Females & $29(35.4)$ & $53(77.9)$ & $82(100)$ & & & & & \\
\hline \multicolumn{9}{|l|}{ Dietary Habits } \\
\hline Vegetarian & $29(32.2)$ & $61(67.7)$ & $90(100)$ & \multirow{2}{*}{1.902} & \multirow{2}{*}{$0.879-4.114$} & \multirow{2}{*}{2.708} & \multirow{2}{*}{1} & \multirow{2}{*}{0.1} \\
\hline Non-Vegetarian & $12(20)$ & $48(80)$ & $60(100)$ & & & & & \\
\hline \multicolumn{9}{|c|}{ Family History of Diabetic Mellitus } \\
\hline Present & $20(60.6)$ & $13(39.4)$ & $33(100)$ & \multirow{2}{*}{7.033} & \multirow{2}{*}{$3.027-16.339$} & \multirow{2}{*}{23.581} & \multirow{2}{*}{1} & \multirow{2}{*}{$0.000^{*}$} \\
\hline Absent & $21(17.9)$ & $96(82.1)$ & $117(100)$ & & & & & \\
\hline \multicolumn{9}{|l|}{$\mathrm{BMI}\left(\mathrm{kg} / \mathrm{m}^{2}\right)$} \\
\hline $\mathrm{BMI} \geq 23$ & $37(90.2)$ & $4(9.8)$ & $41(100)$ & \multirow{2}{*}{5.384} & $1.784-$ & \multirow{2}{*}{10.442} & \multirow{2}{*}{1} & \multirow{2}{*}{$0.001^{*}$} \\
\hline BMI $<23$ & $67(71.7)$ & $39(28.3)$ & $106(100)$ & & 16.249 & & & \\
\hline \multicolumn{9}{|l|}{ Hypertension } \\
\hline No Family History & $26(23.4)$ & $85(76.6)$ & $111(100)$ & \multirow{2}{*}{0.489} & \multirow{2}{*}{$0.224-1.068$} & \multirow{2}{*}{3.286} & \multirow{2}{*}{1} & \multirow{2}{*}{0.07} \\
\hline Either Parents & $15(38.5)$ & $24(61.5)$ & $39(100)$ & & & & & \\
\hline \multicolumn{9}{|l|}{ Physical Activity } \\
\hline Moderate/Vigorous & $5(8.8)$ & $52(91.2)$ & $57(100)$ & 0.112 & \multirow{2}{*}{$0.108-0.136$} & 20.73 & 1 & $<0.0001^{*}$ \\
\hline No/Mild & $41(44.1)$ & $52(55.9)$ & $93(100)$ & & & & & \\
\hline \multicolumn{6}{|c|}{ * P Value is highly significant at 0.01 level of significance } & & & \\
\hline
\end{tabular}

